\title{
RESIDÊNCIA PEDAGÓGICA E FORMAÇÃO DE PROFESSORES EM ALAGOAS: VIVÊNCIAS E REFLEXÕES SOBRE O ENSINO DE LÍNGUA ESPANHOLA
}

\author{
Danillo da Silva Feitosa ${ }^{1}$ \\ Flávia Colen Meniconi ${ }^{2}$ \\ Sérgio Ifa ${ }^{3}$ \\ Jade Neves de Moura Araújo
}

RESUMO: Este trabalho tem por objetivo apresentar algumas reflexões a respeito de uma investigação desenvolvida no Programa Residência Pedagógica (PRP - Espanhol), em especial no que diz respeito à formação de residentes e de professores preceptores do referido programa. Teoricamente, baseamo-nos em estudos acerca da formação de professores (NÓVOA, 1995; DELORS, 2013; MARQUES; PIMENTA, 2015) e na perspectiva do letramento crítico (DUBOC, 2016; MOTTA, 2008; JANKS, 2016). Buscamos, neste estudo, evidenciar a necessidade da formação e da motivação dos professores em relação à construção de novos conhecimentos, respaldados no desenvolvimento da criticidade, reflexão e transformação da prática pedagógica situada. Como instrumentos de coleta de dados, utilizamos a entrevista desenvolvida com as professoras preceptoras e residentes participantes do programa, bem como os relatos provenientes dos relatórios finais produzidos pelos licenciandos. Como resultado da investigação, verificamos que a Residência Pedagógica em língua espanhola da Ufal proporcionou aos participantes a possibilidade de refletirem e (re)pensarem acerca de suas práticas pedagógicas, ressignificando-as.

PALAVRAS-CHAVE: Programa Residência Pedagógica. Formação de professores. Letramento crítico. Língua espanhola.

ABSTRACT: This paper aims to present some reflections on a study carried out in the Pedagogical Residency Program (PRP - Spanish), especially with regard to the education of residents and teachers preceptors of this program. Theoretically, we rely on studies on teacher education (NÓVOA, 1995; DELORS, 2013; MARQUES, THE MARQUES; PIMENTA, 2015) and on critical literacy perspective (DUBOC, 2016; MOTTA, 2008; JANKS, 2016). In this study, we seek to highlight the need for the education and motivation of the teachers in relation to the construction of new knowledge, supported by the development of criticality, reflection and transformation of situated pedagogical practice. The data collection instruments used were the interview with the preceptor teachers and residents participating in the program, as well as the reports from the final reports written by the undergraduates. As a result of the investigation, we found that the Pedagogical Residency Program in Spanish language at Ufal provided the

\footnotetext{
${ }^{1}$ Mestrando em Educação pela Universidade Federal de Alagoas, PPGE/Ufal, Maceió, Alagoas, Brasil. E-mail: q.danillo@gmail.com.

${ }^{2}$ Doutora em Linguística pela Universidade Federal de Alagoas. Professora adjunta do curso de Letras Espanhol da Universidade Federal de Alagoas, Ufal, Maceió, Alagoas, Brasil. E-mail: flavia.meniconi@ fale.ufal.br.

${ }^{3}$ Doutor em Linguística Aplicada pela Pontifícia Universidade Católica de São Paulo. Professor associado do curso Letras Inglês e do programa de pós graduação em Linguística e Literatura da Universidade Federal de Alagoas, Ufal, Maceió, Alagoas, Brasil. E-mail: sergio@ fale.ufal.br.

${ }^{4}$ Mestra em Letras e Linguística pela Universidade Federal de Alagoas, Ufal, Maceió, Alagoas, Brasil. E-mail: jadenevesmoura@gmail.com.
} 
participants with the possibility to reflect on and (re)think about their pedagogical practices, resignifying them.

KEYWORDS: Pedagogical Residency Program. Teacher education. Critical literacy. Spanish language.

\section{Considerações iniciais}

A articulação entre a teoria e a prática é um dos pilares que sustenta a formação dos professores. Nas licenciaturas, essa articulação é, muitas vezes, propiciada pelas disciplinas pedagógicas e pelos estágios supervisionados. O Programa Residência Pedagógica (PRP), ação vinculada à Política Nacional de Formação de Professores, tem como objetivo contribuir para a formação dos alunos matriculados em cursos de licenciaturas, por meio de planejamento e desenvolvimento de ações de intervenção pedagógica, imersão e regência (BRASIL, 2018).

O PRP atende aos alunos das licenciaturas, denominados residentes, matriculados a partir do quinto período do curso de graduação, oportunizando experiências de leituras, discussões teóricas e ações vivenciadas no contexto escolar. No programa, há a participação de profissionais licenciados e em exercício nas escolas-campo, denominados professores preceptores e as atividades desenvolvidas são coordenadas por professores universitários. Um dos objetivos do PRP é oportunizar espaços à preparação de ações que proporcionem processos de ensino-aprendizagem mais motivadores, interessantes e significativos.

De acordo com Ferreira e Siqueira (2020, p. 11), o PRP “é enriquecedor tanto para o licenciando (com relação à sua formação inicial), quanto para o professor preceptor, no que concerne à formação continuada, tendo em vista que ele estará novamente envolto no meio acadêmico", definido pelas autoras como "centro de pesquisa" e "palco de inovações pedagógicas" (FERREIRA SIQUEIRA, 2020, p.11). Assim, o programa pode contribuir para a formação dos professores preceptores, participantes do programa, ao possibilitar momentos de formação, reflexão e transformação da prática de sala de aula. No que tange ao PRP Espanhol da $\mathrm{Ufal}^{5}$, objetivamos propiciar discussões teóricas, desenvolvimento de pesquisas, análises profundas da realidade do contexto escolar, planejamento e implementação de ações no âmbito educacional.

\footnotetext{
${ }^{5}$ Salientamos que o PRP do Curso de Letras da FALE/UFAL recebeu financiamento da CAPES, a quem somos gratos pela oportunidade do trabalho desenvolvido em parceria com as escolas-campo participantes do programa. Agradecemos também pelo investimento das bolsas destinadas aos professores preceptores, supervisores e aos residentes envolvidos no subprojeto multidisciplinar (inglês e espanhol).
} 
Assim, este artigo tem como objetivo relatar e refletir sobre as ações desenvolvidas nas escolas-campo pelos participantes do PRP, na Universidade Federal de Alagoas, principalmente no que diz respeito às vivências dos residentes e de duas professoras preceptoras: Marta e Maria. Para tanto, este trabalho encontra-se dividido da seguinte maneira: (1) seção teórica, na qual trazemos as discussões sobre a formação de professores e a perspectiva do Letramento crítico (doravante LC); (2) metodológica, parte em que explicamos o tipo de abordagem metodológica utilizada para coleta e análise de dados; (3) interpretação de dados, seção em que expomos o estudo e as nossas discussões acerca do corpus da pesquisa; e (4) algumas considerações, nas quais trazemos as reflexões finais acerca da importância do PRP para a formação dos professores envolvidas com o projeto.

\section{Formação de professores e letramento crítico}

A partir de determinadas perspectivas teóricas, a saber: o LC (CERVETTI; PARDALES; DAMICO, 2001; MOTTA, 2008) e a formação de professores (NÓVOA, 1995; DELORS, 2013; MARQUES; PIMENTA, 2015), buscamos evidenciar a necessidade de o profissional da educação se manter atualizado e motivado no que diz respeito à construção de novos conhecimentos, por meio da participação em programas de formação e projetos educacionais voltados para o desenvolvimento crítico, reflexivo e transformador da prática docente.

De acordo com Tozetto (2013), se o professor é o responsável por contribuir para a formação do aluno, este pode auxiliá-lo a ultrapassar os possíveis obstáculos que venham a surgir em sua vida escolar, em especial no que diz respeito à construção do saber. Contudo, é impossível refletirmos quanto ao papel do educador sem pensarmos sobre as mudanças pelas quais a sociedade passa cotidianamente. Nesse contexto de constantes transformações, a necessidade de formações docentes voltadas para o desenvolvimento crítico-reflexivo se faz mais do que urgente. Dessa maneira, fica evidente a importância de o professor se entender como um eterno aprendiz, tendo sempre a consciência de que sua formação não se deu por encerrada com o fim da graduação.

Portanto, a partir das premissas teóricas aqui apresentadas, trazemos a reflexão em relação à importância da mediação entre professores atuantes e professores em formação inicial, pois a colaboração entre docentes e discentes da licenciatura pode, sem dúvidas, ser compreendida como um valioso momento para a troca de saberes e experiências. 
É nesse contexto de aprimoramento do saber que refletimos a respeito do quão interligados estão a "qualidade do ensino" e a "formação do profissional". Sobre isso, Delors (2013) argumenta que a qualidade do ensino é determinada pela formação contínua dos docentes, compreendida como um possível caminho que conduz à percepção da complexidade e dinamicidade da atividade profissional.

Ademais, por ser um dos sujeitos sociais que desempenham uma atividade altamente complexa, defendemos a formação como um continuum (IFA, 2006), ou seja, o docente consciente do seu papel transformador e educativo compreende a necessidade de refletir sobre suas verdades, desconstruindo-as e reconstruindo-as tantas vezes quantas forem necessárias. Nesse sentido, defendemos que o professor precisa ter a ciência de que sua identidade deve estar em constante análise e ressignificação, revendo tradições e refletindo criticamente sobre si e seu exercício diário (MARQUES; PIMENTA, 2015).

Outrossim, ainda sobre o aspecto relativo ao conhecimento acerca do LC, Hoppe (2014) nos alerta para o fato de que, apesar de muitos professores possuírem curso superior, existe a necessidade do investimento em novas práticas, a fim de contribuírem para mudanças relevantes na escola; logo, essas possibilidades devem fazer parte do cotidiano do professor em exercício, e não apenas do profissional em formação inicial. Em outras palavras, faz-se necessário proporcionar aos docentes a oportunidade de conhecer os novos princípios educacionais que surgem diariamente no meio acadêmico, a partir de pesquisas realizadas com os diferentes contextos reais. Faz-se necessário também oportunizar espaços em que docentes, neste caso, os preceptores e residentes, possam expressar suas percepções da prática. A partir disso, espera-se que a troca entre todos os participantes propicie uma leitura crítica da relação entre práticas reais e os princípios, levando em consideração os que mais se adequam à sua realidade educacional e ao fazer educativo contextualizado, e os quais possam ter maior sintonia com a realidade do estudante brasileiro.

Tais aspectos relacionados à formação docente nos levaram ao seguinte questionamento: em que medida a experiência do Programa de Residência Pedagógica em Alagoas contribuiu para a formação de professores? Tal indagação norteou nossa pesquisa e direcionou-a para a busca de reflexões acerca da ressignificação da atuação do professor participante do programa.

Posto isso, acreditamos que o aperfeiçoamento constante dos profissionais da educação é de fundamental importância, já que possibilita ao docente, bem como aos residentes e formadores, a articulação dos conhecimentos adquiridos ao longo de sua experiência, com os 
novos conhecimentos construídos no PRP a partir de leituras, reflexões teóricas, pesquisas e ações desenvolvidas no contexto educacional. Segundo Wengzynski e Tozetto (2012, p. 3), sua importância está na possibilidade de "permitir a aproximação entre os processos de mudança que se deseja fomentar no contexto da escola e a reflexão intencional sobre as consequiências destas mudanças" (sic).

No contexto de ensino e aprendizagem de línguas estrangeiras, defendemos o argumento de que as práticas embasadas/norteadas pelo LC são de fundamental importância para a formação reflexiva, crítica e transformadora dos discentes e professores/as preceptores/as. De acordo com Pinheiro (2019, p. 460), "a criticidade, em sala de aula, serve para desenvolver nos alunos um posicionamento mais questionador e de resistência diante dos discursos dominantes e hegemônicos vigentes, em especial advindos dos meios de comunicação de massa”. Nesse sentido, defendemos que é imprescindível proporcionarmos aos participantes do programa espaços de reflexão e práticas docentes voltadas para (des)(re)construção de saberes e formação de cidadãos mais conscientes e atuantes na sociedade.

Para compreendermos a relevância dessa proposta, retomamos à fala de Bakhtin (1997) sobre a impossibilidade de desvinculação da língua dos seus falantes, da sua realidade e do contexto sócio-histórico-político-cultural em que eles se encontram. Para isso, faz-se necessário entendermos a língua como "um fenômeno social da interação verbal" (BAKHTIN, 1992, p. 123, grifo nosso), ou seja, compreendê-la a partir do contato com o outro, dentro de um contexto específico. Assim, se mudarmos o contexto, mudam, também, os efeitos promovidos pelo que foi dito.

Ainda no que diz respeito à formação crítica, Janks (2016, p. 24) afirma que "toda escolha situa, no primeiro plano, o que foi selecionado e oculta aquilo que não o foi”. É, portanto, subjetiva e tendenciosa. Quer dizer que toda escolha tem um quê e um porquê. Nesse sentido, é importante refletir sobre nossas percepções e concepções, a fim de que possamos pensar sobre os possíveis efeitos dessas escolhas para, assim, agir, questionar, refletir, problematizar, desconstruir e reconstruir - que são, também, características do LC.

Assim, portanto, a inserção de momentos reflexivos sobre o contexto político, histórico, social e cultural na sala de aula torna-se, então, uma necessidade educativa, afinal, contribui para a promoção da reflexão, da atitude questionadora e de ações ativas e transformadoras do contexto social. Em nosso entendimento, essa perspectiva reflexiva é contemplada pelo LC, adotado por nós como aporte teórico para esta pesquisa.

Em suma, com base no exposto, defendemos uma visão de formação de professores que 
caminha em direção à formação crítica, reflexiva, cidadã e transformadora da prática docente. A seguir, discutiremos sobre os aspectos metodológicos que nortearam a condução de nossa pesquisa.

\section{Metodologia}

Expomos, nesta seção, a trajetória metodológica adotada, mais especificamente, o percurso metodológico que orientou o olhar investigativo dos pesquisadores. Destacamos que a investigação se baseou na abordagem qualitativa, já que buscou compreender, de forma mais profunda, o percurso trilhado por duas preceptoras participantes do PRP, na escola-campo em que atuavam junto aos residentes ${ }^{6}$, discentes de Letras/Espanhol.

As escolas nas quais ocorreram as intervenções pedagógicas do PRP Espanhol estão localizadas na cidade de Maceió/AL, mais precisamente nos bairros Benedito Bentes I e Jatiúca. Destacamos ainda que as escolas atuam na modalidade de ensino integral e são umas das poucas instituições de ensino do estado de Alagoas que ainda oferecem a língua espanhola como componente curricular obrigatório em suas grades para o Ensino Médio.

As professoras preceptoras em questão, formadas em Letras/Espanhol pela Universidade Federal de Alagoas, serão mencionadas ao longo do texto como Marta e Maria. Com isso, buscamos respeitar as orientações éticas para pesquisas: o sigilo, o cuidado e a integridade física e mental das colaboradoras supracitadas. Além disso, cabe frisar que, por se tratar de um projeto novo e diferenciado para o cotidiano escolar - modificando em partes a rotina dos educandos -, as docentes buscaram formular um cronograma de dias letivos para o trabalho conjunto com os residentes e a coordenadora do projeto, afinal, era preciso seguir o calendário previsto pela secretaria de educação, bem como os conteúdos pré-estabelecidos.

As atividades que mesclaram a participação das professoras preceptoras, junto aos residentes, como, por exemplo, encontros teórico-metodológicos, planejamentos, desenvolvimentos de projetos e ministração de aula, desenvolveram-se ao longo dos anos de 2018, 2019 e 2020. Durante esses encontros, além de outros conteúdos teóricos-metodológicos (processo de escrita de base retórico-argumentativa, metodologias e ensino de línguas, ensino de leitura a partir de gêneros textuais, entre outros), discutíamos também acerca de teorias e

\footnotetext{
${ }^{6}$ Cabe destacar, para uma melhor compreensão do leitor, que os residentes, com vistas a cumprirem um dos ciclos que abarca a formação inicial docente, atuam juntamente a outros profissionais da escola-campo (professor preceptor, coordenação, direção, etc.). No que tange ao subprojeto de Língua Espanhola da Faculdade de Letras da Universidade Federal de Alagoas, contamos com o total de 16 residentes de língua espanhola, os quais foram divididos entre as escolas participantes do projeto da seguinte forma: 8 graduandos para a escola localizada no bairro do Benedito Bentes I e outros 8 para a escola situada no bairro Jatiúca.
} 
pesquisas desenvolvidas na perspectiva do LC (MOTTA, 2006; ROJO, 2009; MATTOS, VALÉRIO; 2010; MONTE MÓR, 2013; JORDÃO, 2013; DUBOC, 2014; CODEGLIA, 2016; DOS SANTOS; MENICONI, 2018; FEITOSA; MENICONI, 2020) e, com base nas discussões teóricas, pensávamos e planejávamos sequências didáticas para serem desenvolvidas nas escolas-campo pelos participantes do projeto.

Em meados de 2018, quando se iniciaram as atividades do programa na Ufal, os participantes participaram de formações organizadas pela coordenação do PRP Espanhol (oficinas, seminários, discussões teóricas e palestras). Foi a partir de 2019 que Marta, Maria e os residentes, sob a orientação da coordenadora do programa, começaram a planejar e a implementar algumas ações nas escolas-campo, baseadas nas perspectivas da LC.

Para a obtenção dos dados analisados neste trabalho, utilizamos os seguintes os instrumentos de coleta: (1) entrevista oral com ambas preceptoras e (2) relatórios finais dos residentes ${ }^{7}$. Com as entrevistas gravadas objetivamos registrar o diálogo como um todo e captar informações acerca do PRP Espanhol proveniente das falas das entrevistadas. Essas entrevistas contaram com uma lista de indagações que foram respondidas pelas participantes da pesquisa de forma espontânea. Vale destacar que as educadoras estavam cientes de que, embora o instrumento contasse com perguntas pré-elaboradas, outros comentários poderiam ocorrer durante o diálogo. Buscamos, a partir desse tipo de procedimento, uma alternativa diante de uma entrevista puramente mecânica, almejando, assim, o estabelecimento de diálogo informal com as docentes (YIN, 2001; STAKE, 2011).

A investigação possibilitou aos pesquisadores refletir acerca da importância do PRP na formação de professores dos envolvidos com a pesquisa. Além disso, a partir da interpretação dos dados (ver seção seguinte), foi possível evidenciar que, nesta pesquisa qualitativa, os corpora foram instrumentos de suma importância para entendermos o tema aqui investigado.

\section{Interpretação de dados}

Nesta seção, apresentamos a interpretação dos dados a partir dos dados coletados pela entrevista e pelos relatos finais em três subseções que se revelaram significativas na experiência vivenciada pelos participantes: 1 - O que se ganha ao levar as práticas de letramento crítico para a sala de aula?; 2 - Vamos falar de currículo oculto?; 3 - Por que dançar conforme a música?

\footnotetext{
${ }^{7}$ No total, foram analisados 16 relatórios, documentos de caráter obrigatório, exigidos pela CAPES ao final do programa.
} 
O que se ganha ao levar as práticas de letramento crítico para a sala de aula?

Neste tópico, interpretamos as percepções, vivências e experiências das preceptoras construídas no PRP. No primeiro fragmento de fala apresentado a seguir, Marta enfatiza o aprendizado deixado pelo programa em sua trajetória pedagógica, o que nos leva a perceber a relevância desse projeto, conduzindo-nos à seguinte reflexão: que aprendizado seria esse?

\section{Fragmento 1}

Danillo: Se você fosse resumir a sua participação na RP por meio de uma palavra qual seria e por quê?

Marta: Aprendizado.

Danillo: Aprendizado? E por quê?

Marta: Ah, AUTOR, aprendi muito com os residentes... as propostas que levaram, né? O... o olhar, né? O trocar, né... eu aprendi demais... porque assim, algumas das propostas que levaram [...] que a gente, por estar na sala de aula, a gente trabalha, mas a gente não enfatiza. E muitas coisas que a gente trabalhava na escola... eu falo, assim, eu, Marta, sem os residentes... a gente não via dessa forma, né... porque a gente às vezes usava até outra nomenclatura $[\ldots]$ porque até uma figura a gente falava daquela figura, descrevia aquela figura ou retratava aquela figura, mas não sabia a definição correta, e os residentes levaram e deram um banho e foi maravilhoso, que foi o letramento crítico.

No fragmento de Marta, chama-nos à atenção o reconhecimento do LC para a sua formação. Em outras palavras, entendemos que, ao nomear as propostas levadas pelos residentes como "o letramento crítico", Marta já indicava o reconhecimento do trabalho aliado à abordagem teórica estudada e, ao mesmo tempo, o que, em nossa percepção, representava um indício de que estava sendo colocada em prática na escola-campo participante do programa. Sobre esse aspecto, Thewes, Steyer, Fronza (2020, p. 191) salientam que a aprendizagem enquanto processo dialógico pressupõe a co-construção do conhecimento "por intermédio do engajamento em práticas sociais, em que o professor é o mediador. Tendo como foco principal a interação, a prática de letramento torna-se importante não só para o ensino de línguas, mas para todas as áreas". Entendemos, assim, que um dos principais objetivos do LC que associamos ao ensino de língua espanhola foi, então, o de oportunizar a reflexão sobre os posicionamentos e contradições reais existentes em nossa sociedade para, assim, reconstruí-los e/ou transformálos, conforme podemos notar na fala de Maria, abaixo:

\section{Fragmento 2}

Maria: Tudo o que a gente buscava trazer a gente refletia sobre a nossa realidade, né, não só deles, mas de todos. Sobre a realidade da escola, a gente buscava também melhorias, o que é que a gente pode mudar na escola, a participação deles... A escola tem projetos muito interessantes, que vão além, né... [...]. 
PERcursos Linguísticos • Vitória (ES) •v. 11 •n. 27 • 2021 • ISSN: 2236-2592 •

Dossiê: Pibid e RP na formação de professores em Letras •

Para a professora Maria, as atividades desenvolvidas na escola-campo durante o PRP propiciavam reflexão crítica não só dos alunos, mas de todos os envolvidos no programa, o que reflete a nossa proposta inicial de que a formação que almejamos valorizaria as trocas, as interações, os questionamentos para a construção de conhecimentos. Além disso, Maria chama atenção para as possibilidades de transformação do contexto escolar, enfatizando ainda que os projetos desenvolvidos na escola "vão além" ${ }^{8}$, o que corrobora a visão de Duboc (2016, p. 61) acerca do LC entendido "como um exercício de questionamentos das práticas discursivas e como o reconhecimento da relação entre cultura, poder e dominação com vistas à justiça social, igualdade, emancipação e empoderamento".

Acreditamos que esse "ir além" pode representar as oportunidades de pensar criticamente acerca da realidade e mobilizar esforços rumo às mudanças contextuais principalmente em relação à forma de enxergar a si mesmo e ao outro, ressignificando formas de percepções e crenças, muitas vezes, pautadas em visões preconceituosas, injustas e individualistas, tal como pode ser observado no próximo fragmento acerca da importância atribuída ao trabalho crítico reflexivo no que tange à diversidade cultural e identitária dos sujeitos:

\section{Fragmento 3}

Flávia: Como você analisa os aspectos teóricos vistos durante as formações que foram contemplados na prática da RP?

Maria: Então, trabalhamos muita coisa durante as aulas, com a eletiva ${ }^{9}$ a gente discutiu bastante, eram temas mais discursivos. A gente tava conhecendo o outro, então eles podiam ver as diferenças linguísticas, as diferenças sociais, e comparávamos aqui, com o Brasil. Eu gosto muito de falar que para você aprender um novo idioma, você precisa antes de tudo se conhecer, respeitar a sua origem e a partir disso você vai começar a conhecer aquele outro para respeitar aquele outro. Então a gente buscou ensinar as regras gramaticais, os diferentes acentos, mas mais do que isso buscamos refletir sobre aquela outra cultura, sobre aqueles outros países. (...) tem até uma música que eu passei pra eles e essa música se chama iguales e ela fala sobre igualdades. Cada aluno tem a sua identidade então a gente buscava respeitar a cada um, porque é o certo, né? Se eu quero respeito, eu tenho que respeitar o outro. Então essa música é boa porque ela fala sobre igualdade, mas também que cada pessoa é única, que cada pessoa tem a sua singularidade.

\footnotetext{
${ }^{8}$ Desenvolvemos na escola-campo os seguintes projetos: 1- Violência no México: mostra de vídeos, debates e produção textual; 2- Mi barrio (mi mundo): a poluição no entorno da escola; 3 - A morte em outras culturas: projeto "El día de los muertos"; 4- Projeto sobre drogas e seus malefícios.

${ }^{9}$ É importante esclarecer que, durante o desenvolvimento do PRP na escola, a Secretaria da Educação do Estado de Alagoas (SEMED) enviou um ofício ao diretor da instituição, solicitando a retirada do idioma espanhol do ensino integral, sob a justificativa de que apenas os cursos profissionalizantes, tais como: turismo e eventos, deveriam ofertá-lo, a partir daquele momento. Então, após reuniões da coordenadora do PRP (espanhol/FALE/UFAL), juntamente com o gestor de projetos da SEMED, decidiu-se que o idioma poderia permanecer na escola-campo como disciplina eletiva. Compreendemos que essa foi uma grande conquista do programa, já que até os dias de hoje o ensino de espanhol permanece na escola, ainda que de forma eletiva, e com grande procura por parte dos alunos matriculados. Esse foi o caminho que encontramos para evitarmos que saísse do currículo da escola.
} 
Podemos inferir a compreensão de Maria acerca do outro enquanto fator importante na percepção e construção do $e u$. Observamos ainda que a docente se preocupou em trabalhar com os conceitos de cultura e identidade, atentando-se para suas características diversas. Segundo a professora, os participantes do programa buscaram refletir sobre outras culturas, o que também nos levou a perceber, nas entrelinhas de seu discurso, a busca por práticas de ensino direcionadas para uma perspectiva mais crítica e discursiva, principalmente no que tange ao conhecimento das diferenças culturais entre os povos de língua espanhola. Sobre esse aspecto, Duboc (2014, p. 210) argumenta que no contexto globalizado, "a língua estrangeira passa a ser uma das disciplinas mais relevantes na formação crítica e ética do aluno, pois no processo de aprendizagem de uma língua, aprendemos junto com ela aspectos identitários, culturais, sociais e ideológicos".

Ainda sobre as práticas de LC no ensino do idioma espanhol, a docente afirma que:

\section{Fragmento 4}

Maria: Os alunos começaram a se enxergar. A gente ia fazer até um trabalho, era uma peça, que era sobre a consciência negra, então os alunos se empolgaram com o tema que se relaciona com a vida deles, que vem para realidade dele. Eu acho que o bom de trabalhar com a eletiva é que a gente pode trazer mais coisas relacionadas com a realidade deles, e mostrar mais, tipo, que eles podem, que devem lutar pelos direitos dele, que eles são importantes para a sociedade.

De acordo com a professora, o tema referente à consciência negra, trabalhado durante a disciplina eletiva, contribuiu para que os alunos aprofundassem os conhecimentos sobre si mesmos, já que o assunto estava relacionado às realidades deles. Assim, uma vez mais, a experiência relatada pela professora demonstra o quanto as práticas de LC no ensino de línguas parecem ser motivadoras e significativas para si e seus alunos. Acreditamos ainda que tal experiência de ensino reflete o trabalho com o uso da linguagem enquanto prática social, já que propicia o desenvolvimento de ações transformadoras vinculadas à reflexão e ao exercício da cidadania.

No próximo tópico, discorremos sobre o que identificamos como componentes do currículo oculto das preceptoras, isto é, quais sentimentos, percepções, atitudes, crenças e valores beneficiaram positivamente os residentes e as próprias preceptoras.

Vamos falar e discutir sobre o currículo oculto?

Durante as trocas e construção de conhecimento entre residentes, professoras preceptoras e coordenação do programa, faz-se necessário destacar os processos de ensinoaprendizagem resultantes das relações interpessoais desenvolvidas na sala de aula que, de certo modo, não foram colocados de forma explícita - ou seja, não foram prescritos ou planejados 
previamente - mas que surgiram nas situações cotidianas de forma natural, sendo destacadas por alguns estudiosos como os ensinamentos advindos do currículo oculto, aquilo que, a grosso modo, faz parte da dimensão implícita do processo educacional (GIROUX, 1986; BRANDALISE, 2007).

A fim de identificar e analisar características do currículo oculto nas experiências educativas vivenciadas pelos participantes, destacamos os seguintes fragmentos de fala:

\begin{abstract}
Fragmento 5
Danillo: Com relação aos discentes de Letras/Espanhol, quais as dificuldades que eles apresentavam no começo da RP?

Marta: Bom, como sempre, né, quando a gente tá iniciando numa sala de aula, principalmente aqueles que nunca entraram numa sala de aula e se deparam com uma sala de aula com mais de 40 alunos, né, nervosismo, insegurança. Uma das coisas que eu sempre fiz foi deixar muito à vontade, né, sabia intervir na hora certa, sem chamar a atenção de algum deslize dos residentes, porque querendo ou não os alunos percebem tudo, quando tá nervoso, quando não, né? Alguns tremiam até a letra no quadro que a fala, vinha a tosse, e eu: calma. (...) os residentes também souberam, assim, mesmo com o nervosismo, com a insegurança, cultivar, tiveram carisma, simpatia para com os educandos.

Danillo: O que você considera ter ensinado aos residentes?

Marta: Assim, pelo fato de a gente estar numa sala de aula, mesmo fora dela, ser amigos e ter humildade, porque tem muitos profissionais que não tem humildade. Se não souberem de alguma coisa, pergunta, porque a vida é um aprendizado, se não sabe de algo, pergunta. Eu acredito que transmiti segurança para muitos iniciantes que não haviam entrado numa sala de aula. Acho que muitos se espelharão em como lidar com o adolescente em sala de aula, hora de brincar, brincar, hora de falar sério, falar sério, respeito mútuo.
\end{abstract}

\title{
Consideramos o PRP como formação docente porque contribuiu para o
} compartilhamento de novos saberes, os quais, de acordo com as falas acima, foram adquiridos por meio da socialização entre os indivíduos. Nesse sentido, percebe-se, na fala de Marta, que algumas atitudes, comportamentos e orientações vivenciados durante o PRP foram importantes para a formação dos residentes. A exemplo, podemos salientar o nervosismo daqueles que se encontravam em formação inicial e se viam diante de uma sala com 40 alunos. Embora o nervosismo seja o esperado perante a situação, trata-se de um fator que, mesmo fazendo parte do cotidiano escolar, está muito além daquilo que foi planejado ou prescrito previamente no currículo formal. Assim, para lidar com esta situação, a professora preceptora buscou deixar os resistentes "à vontade", a fim de trabalhar a "insegurança", indicando, possivelmente, que alguns conhecimentos relacionados ao fazer docente não faziam parte do planejamento das ações desenvolvidas pelo PRP, mas foram, neste caso, essenciais para o processo de formação inicial dos professores como práticas influenciadas pelos agentes envolvidos no programa (residentes e professor preceptor) por meio do currículo oculto. 
Ainda sobre o conjunto de atitudes, comportamentos e orientações passíveis de observação oriundos da fala da professora Marta, destacamos a alteridade, afinal, o professor enquanto ser social, interage e é interdependente de seus pares. A troca de conhecimentos, em nosso entendimento, permeia a realidade educacional e, muitas vezes, apresenta-se como forma de vivências e experiências presentes nas entrelinhas das relações entre o docente e os licenciandos. Acreditamos que tais interações contribuam para que os licenciandos adquiram experiência e amadurecimento profissional para aprender a lidar com os mais diversos tipos de desafios presentes no fazer docente.

Ainda no que tange ao currículo oculto, apresentamos, a seguir, trechos retirados dos relatórios de alguns dos residentes que atuaram na escola-campo com a professora Marta. Buscamos, aqui, analisar possíveis convergências e/ou divergências presentes nos discursos dos residentes:

\begin{abstract}
Fragmento 6
Sandro: Como ainda era um professor em processo de formação acadêmica, era normal o nervosismo entrar lado a lado comigo na sala de aula. A professora Marta me ajudou a lidar com esse nervosismo e o medo de ter que enfrentar uma sala com muitos alunos cheios de dúvidas. Sempre que eu parecia me perder, a professora entrava em cena com uma explicação mais detalhada, me conduzindo a achar uma melhor maneira de lidar com as situações de dúvidas sobre determinados assuntos que diziam respeito à língua espanhola.

Jaqueline: Houve um momento que eu fiquei receosa com a disciplina na sala de aula, como manter a disciplina com tanto adolescentes cheios de energia, mas a Marta foi bem legal me mostrando como ter a atenção deles, como chamar a atenção e assim de forma mais tranquila começar a aula. Ela me explicou também que esse receio sempre vai haver, sempre iremos ter essa apreensão, esse frio na barriga, mas é isso que nos motiva a melhorar e buscar sempre ministrar uma boa aula.
\end{abstract}

Os relatos de Sandro e Jaqueline revelam momentos importantes em sua formação porque, na prática, em sala de aula, as trocas de informações e orientações com a Marta favoreceram a ambos residentes a lidar com os desafios. Foram talvez gestos, frases e postura corporal que, ao serem compartilhados entre eles, propiciaram o andamento da aula e que marcaram os residentes.

Ao discorrerem sobre os sentimentos de nervosismo e receio durante suas práticas de ensino, os residentes nos remetem à fala da professora preceptora sobre a insegurança inicial percebida no comportamento deles. Acreditamos ainda que, ao valorizarem as habilidades da professora em diferentes situações de ensino e aprendizagem, os licenciandos perceberam que poderiam replicar as condutas, comportamentos e atitudes observadas na prática da professora, em momentos futuros como profissionais. Isso demonstra também que importantes relações de confiança foram desenvolvidas durante as ações do PRP. 
Objetivamos, aqui, descrever e dar visibilidade a algumas atitudes, comportamentos, gestos e percepções das preceptoras considerados como currículo oculto que, segundo Moreira e Candau (2007, p. 18), "envolve dominantemente, atitudes, e valores transmitidos, subliminarmente, pelas relações sociais e pelas rotinas do cotidiano escolar". Pela definição apresentada, é possível pensarmos em vários componentes que fazem parte do currículo oculto, os quais podem ser salutares ou desencorajadoras para o ensino e aprendizagem tais como: a forma como as carteiras são disponibilizadas na sala, a forma como a escola incentiva a chamar a professora, as mensagens implícitas nas falas de docentes e em livros didáticos ou materiais levados à sala de aula, dentre outros.

Pela importância do caráter de influenciar e promover o que consideramos boas práticas docentes, bem como reflexão sobre procedimentos didático-metodológicos e conduta profissional, salientamos que os gestos de carinho, a forma meiga com que Marta e Maria trataram a insegurança dos residentes são atitudes e ações que beneficiam e promovem um futuro positivo e favorável aos residentes iniciantes na docência.

Sublinhamos a necessidade de identificação do currículo oculto manifestado nas escolas-campo se almejamos uma formação crítica para uma sociedade justa e democrática, porque nem sempre é salutar e conveniente como os apresentados pelas preceptoras. Daí, defendemos o argumento de que os valores subjetivos presentes no currículo oculto merecem uma atenção e um lugar especial nos currículos e programas de formação para a docência. Isto é, salientamos, portanto, a necessidade de discussão e problematização.

Por que dançar conforme a música?

Neste tópico, consideramos pertinente tecer algumas considerações sobre o cenário atual no qual vivem os professores de língua espanhola da rede pública de ensino. Há, infelizmente, uma incerteza com relação à permanência da oferta da língua espanhola nos currículos escolares, após a revogação da "lei do espanhol"10. Além desse desserviço à educação dos cidadãos alagoanos, outros dessabores estão presentes na vida dos professores: sobrecarga de trabalho, escassez de tempo para planejamento das aulas, participação em cursos e formações docentes, cobranças burocráticas da escola/secretaria de educação, entre outros. Esses aspectos, além dos planejamentos e calendários pré-definidos, por exemplo, levam o

\footnotetext{
${ }^{10}$ A lei 11.161 foi decretada pelo Congresso Nacional e sancionada pelo então presidente Luiz Inácio Lula da Silva, em 2005, a qual orienta a oferta obrigatória do ensino da língua espanhola nos currículos plenos do ensino fundamental de $5^{\mathrm{a}}$ a $8^{\mathrm{a}}$ séries e ensino médio.
} 
professor a dançar conforme a música, isto é, adaptar-se às novas realidades e imposições. Isso nos faz refletir acerca da importância de o professor que busca promover criticidade e ensino significativo de língua espanhola poder subverter determinadas orientações obrigatórias, por exemplo, para reconfigurar suas ações, visando à formação cidadã dos seus alunos, bem como a sua própria formação.

Dado o exposto, apresentamos, a seguir, as percepções negativas e positivas da formação construída pelos participantes. Iniciamos com Marta, que sinalizou um aspecto não tão positivo: não houve abertura total da escola para o programa.

\section{Fragmento 7 \\ Marta: O que não funcionou bem, assim, ao meu ver, foi em relação a algumas aberturas que a escola não deu pra, no caso, a RP entrar, digamos assim, com tudo. Danillo: Com tudo o quê? \\ Marta: Com tudo assim, com todas as propostas, com todos os planejamentos que vocês fizeram, né, com toda a bagagem que os residentes levaram, né? Então, porque a escola em si, né, você sabe muito bem, né? Tem o seu próprio planejamento, tem o seu próprio calendário, ainda teve algumas situações, né? [...] Então, quer dizer, a abertura, assim, da escola, ela acolheu... mas a gente teve que andar conforme a escola anda.}

De acordo com Marta, não foi possível realizar todas as ações propostas pelo PRP, em função do planejamento e programa da escola-campo. A falta de abertura da escola para o desenvolvimento integral das ações propostas é, por ela destacado, como um dos pontos negativos do projeto. Em relação a esse aspecto, defendemos que a conquista de espaços para o desenvolvimento de práticas transformadoras na escola é o maior objetivo almejado pelo PRP em Língua Espanhola. De forma oposta, opinamos ainda que, dentro das possibilidades do contexto escolar, conseguimos concretizar propostas didáticas que contribuíram para a formação crítica, reflexiva e cidadã dos participantes do PRP, como já relatado nas análises de dados anteriores.

No que tange especificamente às práticas de LC na escola, destacamos uma fala da professora Marta, quando questionada sobre a realização de atividades baseadas nessa perspectiva.

\footnotetext{
Fragmento 8

Danillo: Você acha que é possível trabalhar o Letramento Crítico nas aulas de português?

[Pausa]

Marta: Com certeza, AUTOR. [...] Eu acho que Letramento Crítico não só tá na língua portuguesa não... [...]

Danillo: E você pensa em trabalhar Letramento Crítico agora com o português?

Marta: [...] se eu tiver abertura pra isso... [...] Então, se tiver essa abertura, né, pra trabalhar o Letramento Crítico, com certeza eu irei levantar essa bandeira.
}

No fragmento acima, interpretamos que Marta sinaliza a possibilidade do trabalho com LC em língua portuguesa, se a escola a permitir. Além disso, salientamos que a compreensão 
da docente ratifica a importância do LC para o processo de ensino-aprendizagem de línguas, seja ela qual for. Ao mencionar "se tiver abertura" em sua fala, a professora nos leva a refletir sobre o dilema de Marta: seguir o que é imposto e exigido pela coordenação e/ou secretaria em que conteúdos devem ser trabalhados - ou ensinar de forma significativa, prazerosa, fazendo uso de propostas que favoreçam as trocas e as interações para formação crítica do educando.

De que forma, então, podemos lidar com essa realidade? É possível, diante desse cenário, inserir as reflexões e promover as discussões, tão necessárias para que saibamos questionar, argumentar e agir diante das imposições sociais com as quais nos deparamos quase diariamente? Como podemos conciliar essas propostas com a proposta curricular imposta pelas escolas? Como manter-se motivado para continuar contribuindo com a educação, fazendo aquilo em que nós, professoras e professores, acreditamos?

Essas são perguntas que nos circundam a mente após as reflexões acima apresentadas. Para nós, pensar em educação é tarefa que requer grande cuidado, atenção e responsabilidade, sendo um exercício que deve ser iniciado ainda durante a graduação. Devido a isso, defendemos a importância de um projeto de Residência Pedagógica que possibilite o conhecimento e o desenvolvimento de ações transformadoras da realidade escolar. Dessa forma, acreditamos que teremos, mais a frente, professoras e professores melhor preparados para lidar com o contexto educacional da nossa cidade, conscientes do seu papel transformador.

Para ilustrar os pontos positivos do PRP para a formação docente, apresentamos um fragmento do discurso da discente de Letras/Espanhol, Paula, presente em seu relatório final:

\section{Fragmento 9 - Possibilidades de trabalho \\ Paula: O ponto positivo da experiência na RP com a professora Marta, se deu com a sugestão de que não ficássemos presos no ensino tradicional. Os temas trazidos de acordo com a vivência do aluno, violência urbana, drogas, abriram várias possibilidades de trabalharmos com produção de textos, interpretação leitora e auditiva com o uso de músicas, filmes, curta-metragem, folders e produções de histórias em quadrinhos, além da cultura hispânica que foi representada na culminância de encerramento do ano letivo.}

Compreendemos, assim, que a abertura para inovar na escola-campo em questão, salientada na fala da residente, viabilizou o trabalho com o idioma espanhol a partir de perspectivas mais críticas, reflexivas e transformadoras, tão defendidas nas formações e planejamentos das ações pensadas e definidas conjuntamente com a coordenadora do programa PRP (Espanhol/FALE/UFAL). Essa seria uma maneira de romper os muros do sistema educacional de ensino, muitas vezes engessado e regido pela exposição unicamente às regras gramaticais do idioma, o que, a nosso ver, torna a aprendizagem do idioma desmotivadora e pouco significativa para a formação do cidadão participativo, questionador, crítico e atuante. 
É preciso, portanto, um enfrentamento da realidade. Um posicionamento mais sério diante do cenário no qual estamos inseridos. Não queremos, com isso, colocar professores contra gestores ou contra alunos, pais e responsáveis. O nosso objetivo é o de levar à reflexão sobre a importância de que o professor tenha o espaço necessário para promover discussão de textos com temas relevantes em sala de aula para contextualizar o ensino da língua espanhola. É preciso estar preparado, apto, habilitado para compreender o seu papel docente na sociedade em que está inserido.

Dessa forma, professores preceptores, com experiência de longos anos de exercício da docência, e professores em formação inicial, ansiosos pela oportunidade de vivenciar a experiência da sala de aula e cheios de novos conhecimentos para serem colocados em prática, todos tiveram a oportunidade de crescer juntos, aprendendo uns com os outros e contribuindo, assim, para a realidade da educação no nosso estado.

\section{Algumas considerações}

Foi possível perceber que o PRP contribuiu de forma significativa para os participantes, deixando várias sementes, inúmeros aprendizados, como pontuado pelos participantes da pesquisa. Acreditamos, ainda, que o trabalho norteado pelo LC possibilitou aos participantes a reflexão sobre a importância da formação crítica, reflexiva e transformadora, por meio do ensino do idioma espanhol e, ao mesmo tempo, o desenvolvimento de ações de implementação de projetos pautados na formação para a cidadania.

Gostaríamos de chamar a atenção para o fato de que a importância do trabalho com a perspectiva do LC se mostrou promissora no que tange às sementes plantadas, isto é, novos ensinamentos foram lançados no espaço formativo do PRP, como o ensino da língua espanhol por meio de uma ótica crítica por exemplo. Consideramos um trabalho fértil por ter sido o primeiro em solo alagoano que estava acostumado a outras visões teórico-metodológicas. Reconhecemos, portanto, que em toda formação de professores, bem como em todo processo de ensino, muito se é explorado, e os frutos da aprendizagem nem sempre são visíveis no momento após o ensino. Aprendizagem, assim como os frutos, precisam de tempo para maturar. Por isso, este trabalho inicial com o LC nos deixou esperançosos porque presenciamos possibilidades de um ensino crítico voltado às necessidades e interesses locais dos estudantes.

A relevância de trazer a discussão sobre currículo oculto foi fundamental, pois é um dos elementos constituintes da profissionalização docente. Ressaltamos, no entanto, o que já apresentamos anteriormente, a necessidade de discussão e problematização de seus 
componentes, a saber: atitudes, comportamentos, gestos e percepções, dentre outros. Por conta, às vezes, da sua natureza invisível, tais elementos deixam de ser comentados, discutidos e problematizados em formação docente, o que pode acarretar a reprodução irrefletida porque foram assumidos como corretos, condizentes e/ou promotores de boa aprendizagem. É isso que se precisa problematizar, pois nem todo componente do currículo oculto, por exemplo, pode ser considerado favorável à aprendizagem.

Outro ponto que merece atenção, também evidenciado em nossa análise, diz respeito às exigências (sobrecarga de trabalho, escassez de tempo, etc.) às quais as professoras são submetidas cotidianamente, levando-as, em certos casos, a dançar conforme a música, o que dificulta uma reconfiguração de suas práticas docentes. Ao refletirmos sobre tais imposições, percebemos a necessidade do enfrentamento dessa realidade, por meio da formação de professores (seja ela inicial ou continuada), alicerçada à preparação e à emancipação profissional do docente.

O PRP, nesse contexto, apresentou-se como forma de romper algumas barreiras do sistema educacional de ensino, isso porque proporcionou que os participantes - professoras preceptoras, residentes e coordenadora do programa - voltassem seus olhares à importância de práticas transformadoras das realidades das escolas-campo. Ademais, por meio dele, foi possível concretizar um trabalho voltado para uma formação que compactue com a promoção de uma postura crítica, problematizadora e transformadora da realidade.

Nesse sentido, ressaltamos a contribuição desta pesquisa para os profissionais da educação que atuaram/atuam ou, ainda, os que irão atuar em edições futuras como preceptores, especificamente no que diz respeito à importância de levar residentes e preceptores a perceberem o PRP como uma excelente oportunidade de formação docente.

Por fim, destacamos que a atuação das professoras preceptoras ultrapassou o papel de meras mediadoras do "conhecimento em processos de aprendizagem e desenvolvimento dos graduandos" (GONÇALVES; DA SILVA; DAS GRAÇAS BENTO; 2019, p. 678), isso porque o PRP possibilitou o exercício da autorreflexão, o que levou os participantes a repensarem sobre suas práticas, por meio das experiências vivenciadas, e a ressignificarem crenças e ações relacionadas ao processo ensino e aprendizagem da língua espanhola.

\section{Referências}

BAKHTIN, M. Estética da criação verbal. 2. ed. São Paulo: Martins Fontes, 1997. 
BAKHTIN, M. Marxismo e Filosofia da Linguagem. São Paulo: Hucitec, 1992.

BRANDALISE, M. A. T. Currículo e práticas pedagógicas. Ponta Grossa: UEPG, 2007.

BRASIL, Programa Residência Pedagógica. Fundação CAPES, 01 mar. 2018. Disponível em: https://capes.gov.br/educacao-basica/programa-residencia-pedagogica. Acesso em: 20 dez. 2020.

CERVETTI, G.; PARDALES, M. J.; DAMICO, J. S. A tale of differences: Comparing the traditions, perspectives, and educational goals of critical reading and critical literacy. Reading online, v. 4, n. 9, p. 80-90, 2001. Disponível em: https://www.researchgate.net/profile/Gina_Cervetti/publication/334372467_A_Tale_of_Diffe rences_Comparing_the_Traditions_Perspectives_and_Educational_Goals_of_Critical_Readin g_and_Critical_Literacy/links/5d25e94e92851cf4407535a3/A-Tale-of-DifferencesComparing-the-Traditions-Perspectives-and-Educational-Goals-of-Critical-Reading-andCritical-Literacy.pdf. Acesso em: 06 jan. 2021.

CODEGLIA, A. F. Letramento Crítico e Ensino de Língua Espanhola: Analisando Atividades de Leitura do Livro Didático Cercanía Joven. Porto das Letras, v. 1, n. 2, p. p. 22 - 45, 31 mar. 2016. Disponível em: https://sistemas.uft.edu.br/periodicos/index.php/portodasletras/article/view/1863 Acesso em: 11 mar. 2021.

DELORS, J. O tesouro interior: Aprender a saber, aprender a fazer, aprender a viver juntos e aprender a ser. Qual o valor desse tesouro 15 anos após sua publicação? Revista Internacional de Educação, v. 59, n. 3, p. 319-330, 2013.

DOS SANTOS, G. C.; MENICONI, F. C. Ensino-aprendizagem de Língua Espanhola no Projeto Casas de Cultura no Campus da Universidade Federal de Alagoas: propostas e encaminhamentos para formação crítica. Leitura, v. 2, n. 61, p. 115-136, 2018. Disponível em: https://www.seer.ufal.br/index.php/revistaleitura/article/view/5474. Acesso em: 15 mar. 2021.

DUBOC, A. P. M. Letramento crítico nas brechas da sala de aula de línguas estrangeiras. In: TAKAKI, N. H.; MACIEL, R. F. (Org.). Letramentos em terra de Paulo Freire. Campinas: Pontes Editores, 2014. p. 209-230.

DUBOC, A. P. M. A avaliação da aprendizagem de línguas e o letramento crítico: uma proposta. In: JESUS, D. M. de; CARBONIERI, D. (Org.). Práticas de Multiletramentos e Letramento Crítico: outros sentidos para a sala de aula de línguas. Campinas, SP: Pontes Editores, 2016, (Coleção Novas Perspectivas em Linguística Aplicada, 47).

FEITOSA, D. S.; MENICONI, F. C. Produção textual na universidade: o ensino-aprendizagem da escrita argumentativa em língua espanhola por meio da perspectiva do letramento crítico. In: DA SILVA, E. B.; SILVA JÍNIOR, S. N. (Orgs.). Na sala de aula, a língua e a literatura. Arapiraca: Eduneal, 2020.

FERREIRA, P. C. C.; SIQUEIRA, C. S. Residência Pedagógica: um instrumento enriquecedor no processo de formação docente. Revista Práticas de Linguagem, Juiz de Fora, v. 10, n. 1, $\mathrm{p}$ 7-19, 2020. 
<https://periodicos.ufjf.br/index.php/praticasdelinguagem/article/view/31448>. Acesso em: 19 jan. 2021. DOI: https://doi.org/10.34019/2236-7268.2020.v10.31448

GIROUX, H. Teoria crítica e resistência em educação (para além das teorias da reprodução) Petrópolis, Vozes, 1986.

GONÇALVES, S. M. S.; DA SILVA, J. F.; DAS GRAÇAS BENTO, M. Relato sobre o Programa de Residência Pedagógica: Um olhar sobre a Formação Docente/Report on the Pedagogical Residence Program: A look at the Teacher Education. ID on line Revista de psicologia, v. 13, n. 48, p. 670-683, 2019. Disponível em: <https://idonline.emnuvens.com.br/id/article/view/2268>. Acesso em: 19 jan. 2021.

HOPPE, M. C. A formação de professores: o letramento crítico na sala de aula e as práticas sociais. Uniletras, Ponta Grossa, v. 36, n. 2, p. 201-209, jul/dez. 2014. Disponível em: <http://www.revistas2.uepg.br/index.php/uniletras>. Acesso em: 08 jun. 2021.

IFA, S. A formação pré-serviço de professores de língua inglesa em uma sociedade em processo de digitalização. 2006. 287 f. 2006. Tese de Doutorado. Tese (Doutorado em Linguística Aplicada e Estudos de Linguagem) - Pontifícia Universidade Católica de São Paulo, São Paulo. Disponível em: https://sapientia.pucsp.br/bitstream/handle/13797/1/SergioIfa.pdf. Acesso em: 15 mar. 2021.

JANKS, H. Panorama sobre letramento crítico. In: JESUS, D. M.; CARBONIERI, D. (Orgs.) Práticas de Multiletramentos e Letramento Crítico: Outros sentidos para a Sala de Aula de Línguas. Campinas, SP: Pontes Editores, 2016, p. 21-39.

JORDÃO, C. Abordagem comunicativa, pedagogia crítica e letramento crítico - farinhas do mesmo saco? In: ROCHA, C. H.; MACIEL, R. F. Língua estrangeira e formação cidadã: por entre discursos e práticas. Campinas: Pontes, 2013. p. 69-90.

MATTOS, A. M. A.; VALÉRIO, K. M. Letramento crítico e ensino comunicativo: lacunas e interseções. Revista Brasileira de Linguística Aplicada, v. 10, n. 1, p. 135-158, 2010.

Disponível em: <http://www.scielo.br/pdf/rbla/v10n1/08.pdf>. Acesso em: 06 jul. 2015.

MARQUES, A. C. T. L.; PIMENTA, S. G. É possível formar professores sem os saberes da pedagogia? : uma reflexão sobre docência e saberes. Revista Metalinguagens, n. 3, p. 135$156,2015$.

MONTE MÓR, W. Crítica e letramentos críticos: reflexões preliminares. In: ROCHA, C. H.; MACIEL, R. F. Língua estrangeira e formação cidadã: por entre discursos e práticas. Campinas: Pontes, 2013. p. 31-50.

MOREIRA, A. F. B.; CANDAU, V. M. Indagações sobre currículo: currículo, conhecimento e cultura. Organização do documento Jeanete Beauchamp, Sandra Denise Pagel, Aricélia Ribeiro do Nascimento. - Brasília: Ministério da Educação, Secretaria de Educação Básica, 2007. Disponível em: portal.mec.gov.br/seb/arquivos/pdf/Ensfund/indag3.pdf. Acesso em 05.mar.2021.

MOTTA, A. P. F. O letramento crítico no ensino/aprendizagem de língua inglesa sob a perspectiva docente. Londrina, 2008. Disponível em: 
<http://www.diaadiaeducacao.pr.gov.br/portals/pde/arquivos/379-4.pdf >. Acesso em: 20 de nov. 2020.

NÓVOA, A. Formação de professores e profissão docente. In: Nóvoa, A. Os professores e sua formação. Lisboa: Dom Quixote, 1995.

PINHEIRO, M. S. O letramento multimodal crítico: o discurso discente sobre política nas aulas de espanhol. Revista Brasileira de Linguística Aplicada, v. 19, n. 3, p. 455-476, 2019.

ROJO, R. Letramentos múltiplos, escola e inclusão social. São Paulo: Parábola Editorial, 2009. 128 p.

STAKE, R. E. Pesquisa qualitativa: estudando como as coisas funcionam. Porto Alegre: Penso, 2011.

THEWES, J. D. L.; STEYER, D.; FRONZA, C. A. Reflexões sobre letramento crítico nas aulas de línguas estrangeiras a partir de uma perspectiva trazida pela Base Nacional Comum Curricular. Revista Gelne, v. 22, n. 1, p. 188-202, 2020. Disponível em: <https://periodicos.ufrn.br/gelne/article/view/19292>. Acesso em: 19 jan. 2020.

TOZETTO, S. S. O processo de formação continuada da docência. In: RAIMAN, A. Formação de professores e práticas educativas: outras questões. RJ: Editora Ciência Moderna, 2013.

WENGZYNSKI, C. D.; TOZETTO, S. S. A formação continuada face as suas contribuições para a docência. In: $\mathbf{9}^{\mathbf{a}}$ ANPED SUL. 2012. Disponível em: <http://www.ucs.br/etc/conferencias/index.php/anpedsul/9anpedsul/paper/view/2107>. Acesso em: 19 jan. 2021.

YIN, R. K. Estudo de Caso: planejamento e métodos. 2. ed. Porto Alegre: Bookman, 2001. 